\title{
Comparative Analysis of a 15 Story Flat Plate Building with and Without Shear Wall and Diagonal Bracing Under Wind and Seismic Loads
}

\author{
Rajib Kumar Biswas ${ }^{1}$, Md.Meraj Uddin ${ }^{2}$, Md.Arman Chowdhury ${ }^{3}$, \\ Md.Al-Imran Khan ${ }^{4}$ \\ I' Graduate student, Department of Civil Engineering, Ahsanullah University of Science and Technology) \\ ${ }^{2}$ (Graduate student, Department of Civil Engineering, Ahsanullah University of Science and Technology) \\ 3 ( Graduate student, Department of Civil Engineering, Ahsanullah University of Science and Technology) \\ ${ }^{4}$ ( Graduate student, Department of Civil Engineering, Ahsanullah University of Science and Technology)
}

\begin{abstract}
A flat plate is a reinforced concrete slab supported directly by concrete columns without the use of beams, column flares or drop panels. Flat plate system has been adopted in many buildings constructed recently taking advantage of the reduced floor height to meet the economical and architectural demands. However, In Multistoried structures the flat plate floor system has week resistance to lateral loads like wind and earthquake hence this paper is concerned to increase lateral stiffness of flat plate structure and to minimize the displacement of the structure under lateral loading. This paper is also concerned about column axial load and to review our structure with special features like shear walls \& diagonal bracing. In present work, a 15 storied flat plate garments building have been modeled using software package "STAAD Pro" for earthquake zone II in Bangladesh.This model is considered in most vulnerable situation where we took wind speed as $260 \mathrm{kmph}$ and Earthquake load has been taken as per Bangladesh National Building Code(BNBC)
\end{abstract}

Keywords: Shear wall, Diagonal bracing, Lateral stiffness, Flat plate

\section{INTRODUCTION}

From the beginning flat plate attracts the eye of architectures for its beautiful view and of engineers for its reduced floor height. But its demands get down because of its weakness to lateral forces. Because it does not allow any beam at its edge so necessarily due to deflection control slab thickness needs to be increased. So, question may arise why not to be concerned by gravity load. Gravity load although does not concern us but there is a provision for increasing the column section to a great extent or provide great thickness of bearing wall. After that, it still cannot be ruled out that gravity load has a great relation with seismic forces. So threat continues to exert on flat plate. To minimize that, like in many research, in this paper it will be clarified that lateral stiffness is the key. To analyze that in this paper structural software STAAD Pro will be used. Lateral drift and displacement will also be a matter of discussion in this study as these have an important relationship with structures lateral stiffness. After the work has given its' what, why and how results will be depicted to provide final observation and thus will give a good decision making conditions.

\section{OBJECTIVE OF THE STUDY}

We execute this research to improve the condition of flat plate structure. In the present scenario flat plate is considered as a risky structure. So we focus on a multi bay flat plate building

- To analyze the structural behaviors of flat plate using X bracing, shear wall in structural analysis software 'STAAD Pro'.

- Study on X-bracing system and shear wall by providing them to flat building to increase lateral stiffness.

- To analyze the structures with different case studies.

\section{Detalls Of The Present Study \\ General \\ Whenever we talk about a structure we always think about the loads it carries and its resistivity against it. For that, we have to know about that structures force, moment, stress and displacement. As we will try to increase lateral stiffness of a 15 -storied flat plate garment building so in this segment of our work we will show our data about axial force and displacement which is obtained by STAAD Pro software analysis.}




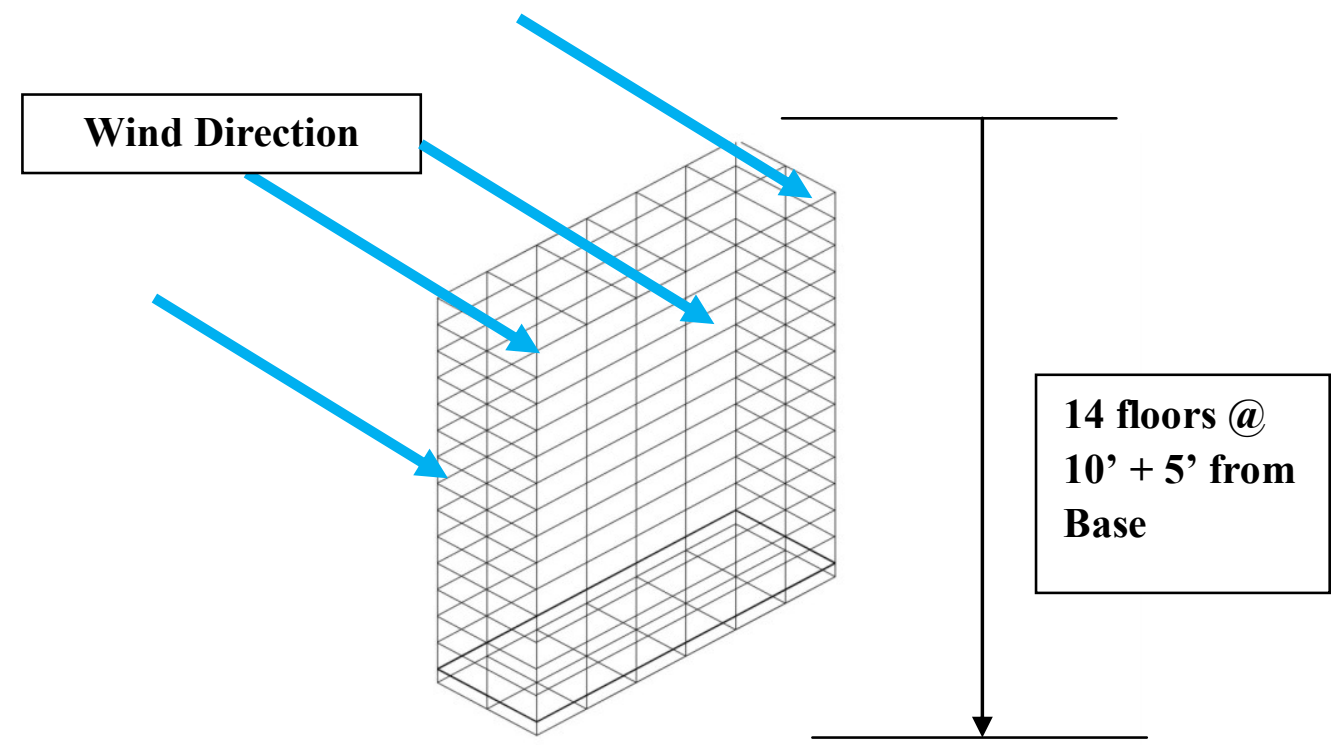

Figure 01: Conceptual Frame View (Grid Division).

\section{Details of the Models}

The model which has been adopted for study is a 15 story regular garments building. The building is consisting of four different types of square columns with dimension 30 in x30 in, 27 in x 27 in,24 in x 24 in and $20 \mathrm{in} \mathrm{x} 20 \mathrm{in}$. The floor slabs are taken as .791 ft thick. The modulus of elasticity and shear modulus of concrete have been taken as $\mathrm{E}=2.48 \times 107 \mathrm{kN} / \mathrm{m} 2$ and $\mathrm{G}=1.03 \times 107 \mathrm{kN} / \mathrm{m} 2$.

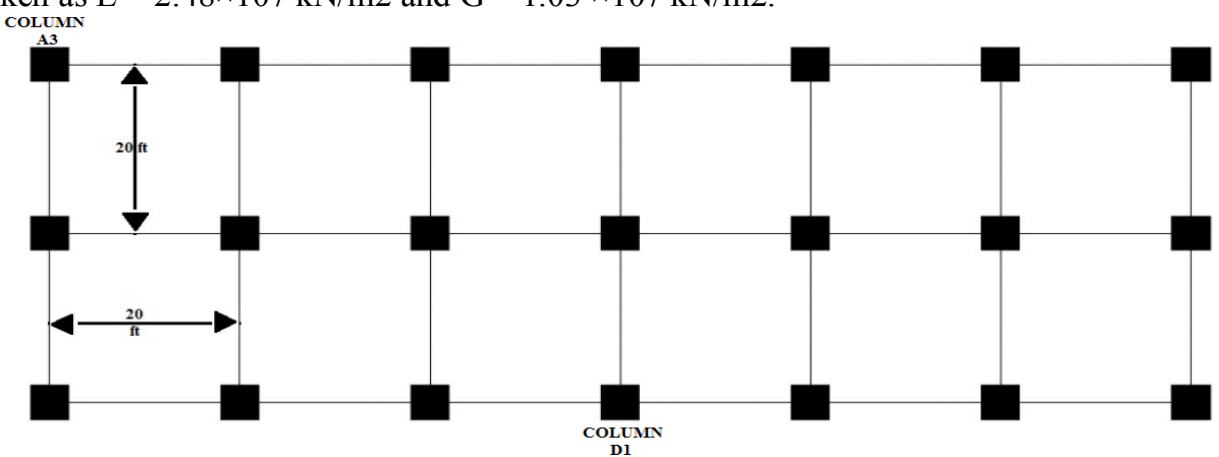

Fig 02: General plan view of a 15 story garments building

Here we studied 4 different cases. Case 01 has diagonal Bracing only at exterior, in Case 02 there is bracing at both interior and exterior. In case 03 there is Shear Wall at exterior where as in case 04 there is Shear wall at both interior and exterior. In this study Shear wall section are taken as 12 inch thick and Diagonal bracing are taken as 12 in $\times 12$ inch.

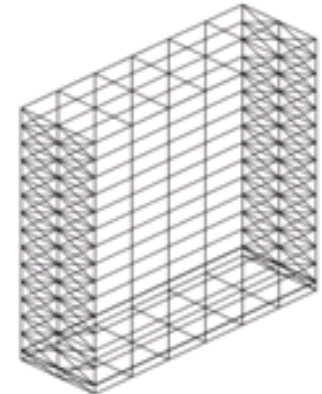

Fig 03: Case01: Diagonal Bracing at Exterior

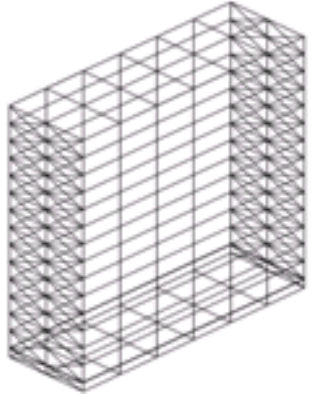

Fig 04:Case02: Diagonal Bracing at Exterior and Mid 


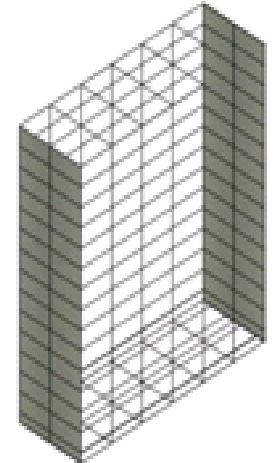

Fig 05:Case03 (Shear Wall at Exterior)

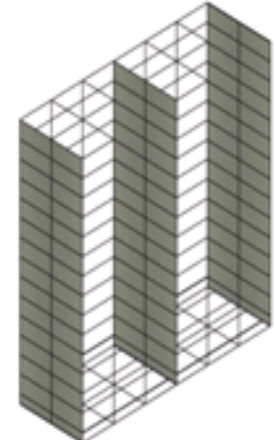

Fig06:Case04(Shear Wall at Exterior and Mid)

\section{Load combination}

In this study we consider four different load combinations as per BNBC recommendation for dead \& live loadings and seismic \& wind loading. The load combinations are

Load Combination 1: 1.4DL + 1.7LL.

Load Combination 2: $1.05 \mathrm{DL}+1.275 \mathrm{LL}+1.275 \mathrm{~W}$.

Load Combination 3: $1.05 \mathrm{DL}+1.275 \mathrm{~L}+1.4 \mathrm{E}$.

Load Combination 4: 1.4(D + L + E).

Where,

$\mathrm{D}=$ Dead Load for Self weight, Partition Wall and Floor Finish.

$\mathrm{L}=$ Live Load.

$\mathrm{W}=$ Wind Load.

$\mathrm{E}=$ Earthquake Load.

\section{RESULTS AND DISCUSSION}

Variation Of Lateral Displacement With Height:

Equivalent static method is a linear static method for the seismic analysis. Fig 07, Fig 08, Fig 09 illustrate the comparison of lateral displacement between GENERAL flat plate building and flat plate building having EXT SW, EXT \& MID SW,EXT BRACING,EXT \& MID BRACING for load combination 02,03 and 04. This comparison is showing the values of column A3. Here we see displacement for general flat plate building crosses the limitation recommended by BNBC, whereas for EXT \& MID SW case the displacement reduced abruptly. It is observed that the lateral displacement for Case I are decreased by $49.3 \%$ compared to general Case, lateral displacement for Case II are decreased by 53\% compared to general Case , lateral displacement for Case III are decreased by $64 \%$ compared to general Case, lateral displacement for Case IV are decreased by $74 \%$ compared to general Case for load combination 02 . Lateral displacement for Case I are decreased by $43 \%$ compared to general Case , lateral displacement for Case II are decreased by $47 \%$ compared to general Case , lateral displacement for Case III are decreased by59\% compared to general Case , lateral displacement for Case I are decreased by $71 \%$ compared to general Case for load combination 03.Also lateral displacement for Case I are decreased by $44 \%$ compared to general Case, lateral displacement for Case II are decreased by $48 \%$ compared to general Case, lateral displacement for Case III are decreased by $60 \%$ compared to general Case, lateral displacement for Case IV are decreased by $71 \%$ compared to general Case for load combination 04 .

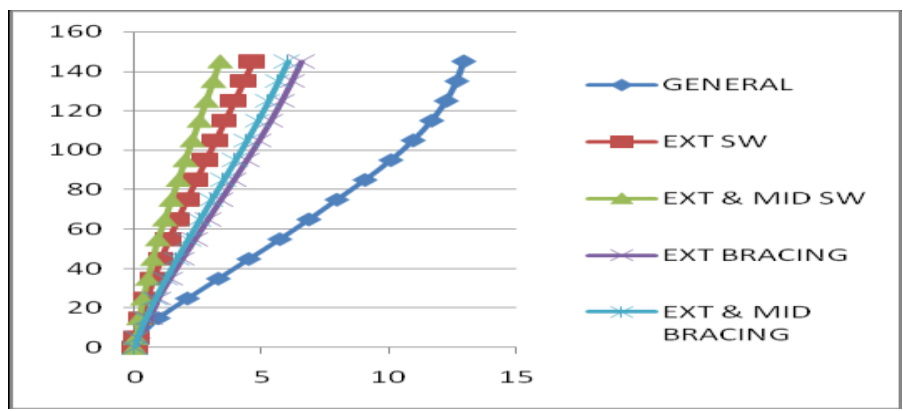


Fig 07: The comparison of lateral displacement between GENERAL flat plate building and flat plate building having EXT SW, EXT \& MID SW,EXT BRACING,EXT \& MID BRACING for load combination 02

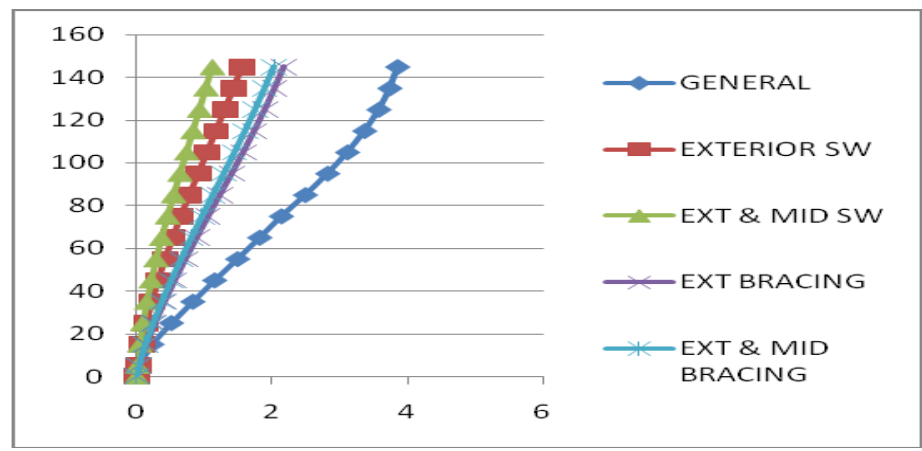

Fig 08: The comparison of lateral displacement between GENERAL flat plate building and flat plate building having EXT SW, EXT \& MID SW,EXT BRACING,EXT \& MID BRACING for load combination 03

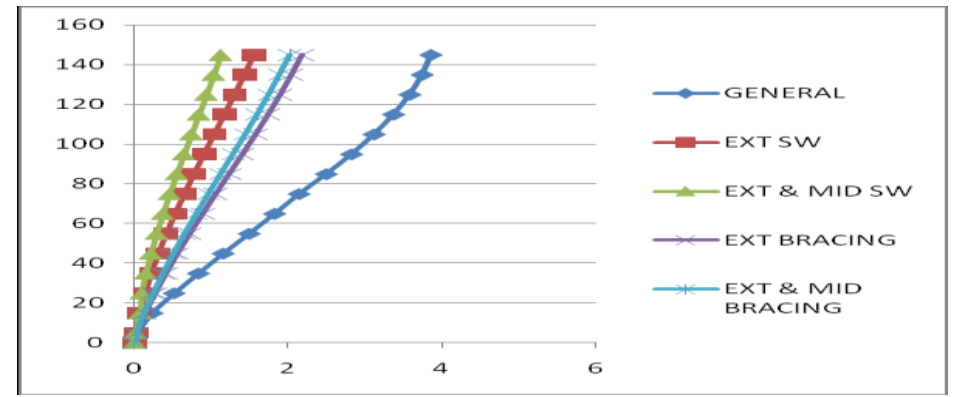

Fig 09: The comparison of lateral displacement between GENERAL flat plate building and flat plate building having EXT SW,EXT \& MID SW,EXT BRACING,EXT \& MID BRACING for load combination 04

\section{Variation Of Axial Load:}

We notice column axial load is also a matter of concern. Fig 10, Fig 11, Fig 12 and Fig 13 illustrate The comparison of axial load of column D1 between GENERAL flat plate building and flat plate building having EXT SW,EXT \& MID SW,EXT BRACING,EXT \& MID BRACING for load combination 01,02,03 and 04.From the following comparisons we notice Shear wall reduce the column axial load comprehensively.

It is observed that the column axial load for Case IV are decreased by 53\% compared to general Case for combination 01, column axial load for Case IV are decreased by $30 \%$ compared to general Case for combination 02, column axial load for Case IV are decreased by $28 \%$ compared to general Case for combination 03, column axial load for Case IV are decreased by 36\% compared to general Case for combination 04 .

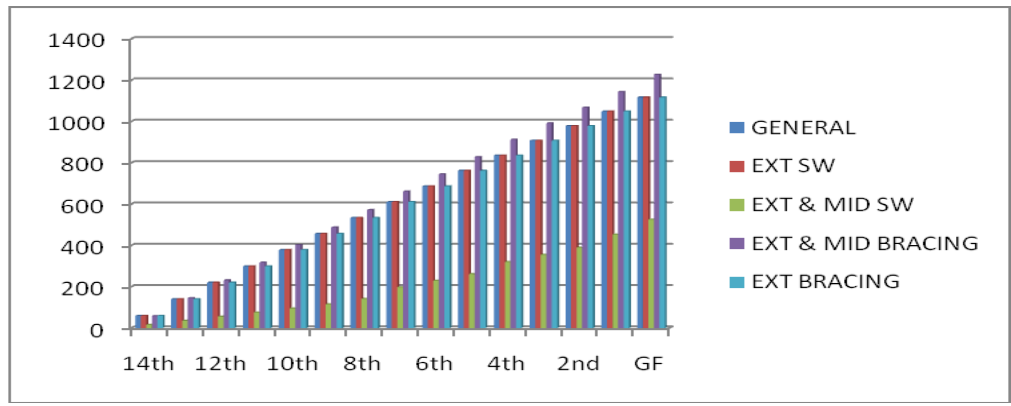

Fig 10: The comparison of axial load of column D1 between GENERAL flat plate building and flat plate building having EXT SW,EXT \& MID SW,EXT BRACING,EXT \& MID BRACING for load combination 01 


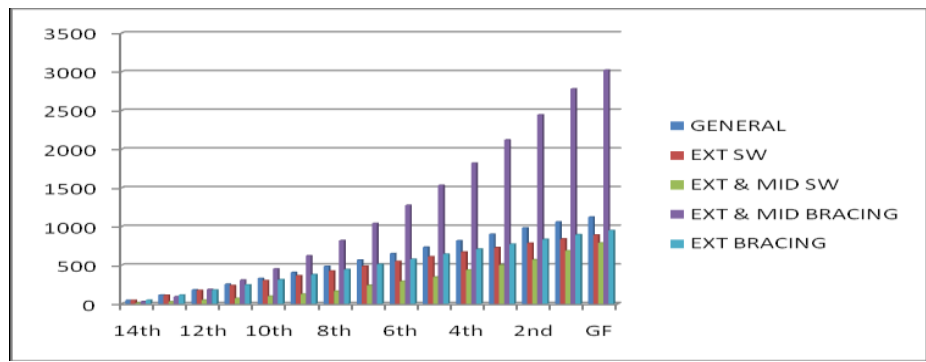

Fig 11: The comparison of axial load of column D1 between GENERAL flat plate building and flat plate building having EXT SW,EXT \& MID SW,EXT BRACING,EXT \& MID BRACING for load combination 02

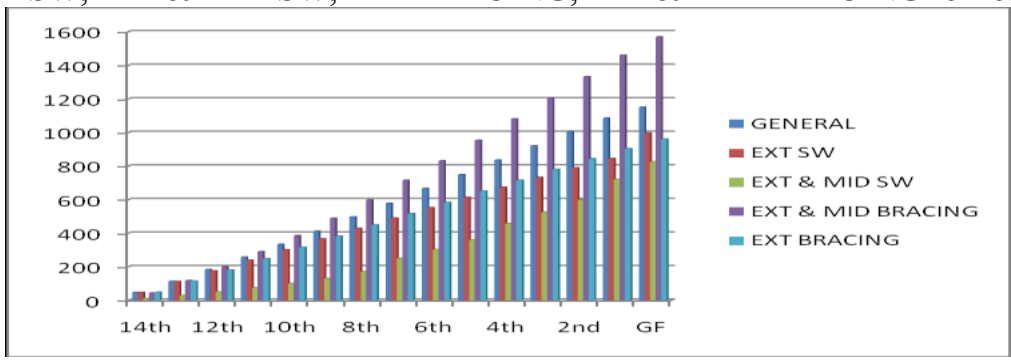

Fig 12: The comparison of axial load of column D1 between GENERAL flat plate building and flat plate building having EXT SW,EXT \& MID SW,EXT BRACING,EXT \& MID BRACING for load combination 03

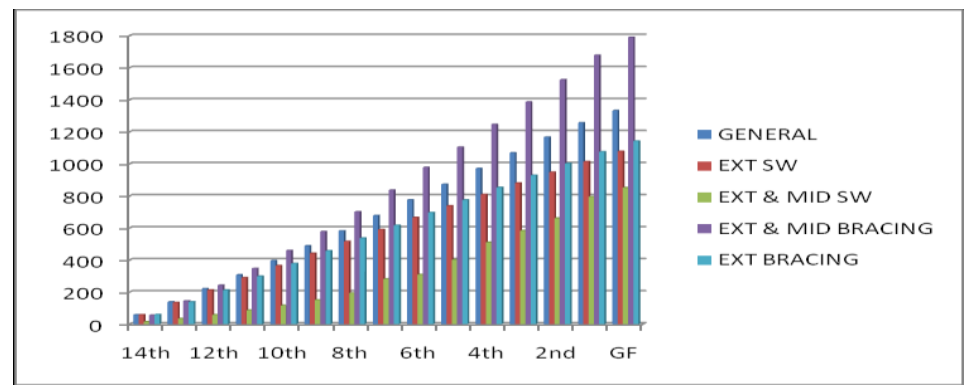

Fig 13: The comparison of axial load of column D1 between GENERAL flat plate building and flat plate building having EXT SW,EXT \& MID SW,EXT BRACING,EXT \& MID BRACING for load combination 04

\section{CONCLUSION}

Flat plate is good in perspective of gravity load. But it experienced that flat plate building can't stand strongly against wind, seismic or other lateral forces. As a result, more than any other structural component, the lateral force-resisting structure has significant impact on space planning. So it is essential for a structure to have lateral resistance. To do the initial schematic design in right way it is important to recognize that it is critical to consider lateral forces from the very start and to integrate lateral force -resisting structure. From the experience of our study we will recommend Shear wall to implement in flat plate structure.

\section{REFERENCES}

[1] H.S.Kim, D.G.Lee, Efficient Analysis of Flat Plate Structures subjected to Lateral Loads, Science Direct, Engineering Struc tures Journal, Vol.27, Issue.2, January 2005, pp 251-263.

[2] Husam Omar, Glenn Morris; Analysis of laterally loaded flat-plate structures, Canadian Journal of structural engineering, Vol.18, No.1, 1991, pp.109-117.

[3] L.G. Jaeger, A.A. Mufti, J.C. Mamet, The structural analysis of tall buildings having irregularly positioned shear walls, Journal of Building Science, Vol.8, pp.11-22. Pergamum Press 1973

[4] Fayazuddin Ahmed Syed, B. Dean Kumar, Y. Chandrasekhar, B.L.P. Swami, Comparative Analysis of Flat Plate Multistoried Frames With and Without Shear Walls under Wind Loads, International Journal of Engineering and Advanced Technology (IJEAT) ISSN: 2249 - 8958, Volume-2, Issue-1, October 2012

[5] IS: 875(Part 3)-1987, "Code of Practise for Design Loads (Other than earthquakes) for Buildings and Structures", Part 3 Wind Loads, Second Revision, Bureau of Indian Standards, New Delhi, 1989.

[6] Mehmet Emin Kara and Sinan Altin, Strengthening of RC non ductile frames with RC Infills : An Experimental Study, Science Direct, Cement and Composite journal, Vol.34, Issue.7, August 2008, pp 612-621. 